\title{
The role of the queen mandibular gland pheromone in honeybees (Apis mellifera): honest signal or suppressive agent?
}

\author{
Katrin Strauss ${ }^{1}$, Holger Scharpenberg ${ }^{1}$, Robin M. Crewe ${ }^{2}$, Felix Glahn ${ }^{3}$, Heidi Foth ${ }^{3}$ \\ and Robin F. A. Moritz ${ }^{1,2}$
}

(1) Institut für Biologie, Martin-Luther-Universität Halle-Wittenberg, Hoher Weg 4, 06099 Halle (Saale), Germany

(2) Department of Zoology and Entomology, University of Pretoria, Pretoria, South Africa

(3) Institut für Umwelttoxikologie, Martin-Luther-Universität Halle-Wittenberg, 06112 Halle (Saale), Germany

Robin F. A. Moritz

Email: r.moritz@zoologie.uni-halle.de

\begin{abstract}
Queen pheromones interfere with worker reproduction in social insects. However, there is still an unresolved question as to whether this pheromone acts as an "honest" signal for workers, giving a reliable indication of the queen's reproductive value, or as a suppressive agent, inhibiting worker reproduction independent of the queen's reproductive capacity. In honeybees (Apis mellifera), the queen's mandibular gland secretion, a mix of fatty acids and some aromatic compounds, is crucial for regulating the reproductive division of labor in the colony inhibiting ovary development in workers. We quantified the mandibular gland secretions of virgin, drone-laying, and naturally mated queens using gas chromatography to test whether the queens' mating, ovary activation, or the reproductive value for workers correlated with the composition of the secretion. Although the absolute amounts of the "queen substance" 9-oxo-2(E)-decenoic acid (9ODA) were similar among the three groups, the proportions of 9-ODA decreased with increasing reproductive quality. Furthermore, the ratios of queen to worker compounds were similar in all three treatment groups, irrespective of the reproductive capacity. A multivariate analysis including all six compounds could not separate drone-laying queens from naturally mated ones, both with active ovaries but only the latter ensuring colony survival. We suggest that the mandibular gland pheromones are unlikely to function as reliable indicators of queen reproductive value and rather operate as an agent to suppress worker reproduction. This does not exclude the possibility that other "honest" pheromone signals exist in the honeybee colony, but these would have to arise from other semiochemicals, which could be produced by both the queen and the brood.
\end{abstract}




\section{Introduction}

The sophisticated colony organization of eusocial Hymenoptera arises from the pronounced reproductive division of labor among its female members. Reproduction is typically monopolized by one or several queens and workers have undeveloped ovaries. As workers do not reproduce, they have no direct fitness but they do gain indirect fitness by rearing sisters and brothers as sexual reproductives (Hamilton 1964). Nevertheless, there is an ongoing conflict over male production as some workers still have the potential to reproduce by laying unfertilized eggs after removal of the reproductively dominant females (Bourke 1988; Page and Erickson 1988). As a consequence, reproductive division of labor is not irreversible and depends on a variety of environmental and social factors. The regulation of reproduction can be mediated through various mechanisms including the queen's pheromonal and/or behavioral signals. In small colonies such as those of permanently queenless ants (Peeters et al. 1999) and Polistes wasps (Fletcher and Ross 1985), aggressive interactions result in dominance hierarchies. In larger colonies, however, this is no longer effective (Engels 1986; Hoover et al. 2003; Dietemann et al. 2003) and pheromonal signals are involved in the regulation of the reproductive hierarchies. These pheromones can be spread throughout the whole colony even if the queen's physical contact is limited to a small proportion of the individuals, either by workers (Naumann et al. 1991; Seeley 1979) or by the brood (Endler et al. 2004).

Initially, a dominance hierarchy model was used to explain the mode of pheromone operation. The queen's pheromones were interpreted as coercive agents to suppress the workers' reproduction (Fletcher and Ross 1985). Because workers develop their ovaries and lay eggs almost exclusively under queenless conditions (Fletcher and Blum 1981; Visscher 1989), it seemed plausible that workers were chemically repressed in the presence of a queen. Inspired by the ideas of inclusive fitness theory, Keller and Nonacs (1993) argued that this mode of action would not be an evolutionary stable strategy since workers should evolve escaping the control mechanisms which act against their own fitness. Evolution should favor workers, who could overcome the queen's suppression by developing resistance to the physiological effects of her pheromones (West-Eberhard 1981). Based on these theoretical considerations, an alternative model known as "worker control" was presented (Seeley 1985; Keller and Nonacs 1993). Here, the queen's pheromones are seen as an "honest" chemical signal to indicate the presence of the queen and her fertility (Peeters et al. 1999; D'Ettorre et al. 2004). With this information, workers could actively decide to refrain from reproducing when benefits from indirect fitness exceed those of direct individual fitness. When workers perceive a decline in the fecundity of the queen, they can activate their ovaries to produce sons themselves. Both of these models have passionate proponents, but experimental evidence that would discriminate between the models has not been provided.

The honeybee, Apis mellifera, is the best studied social insect concerning queen pheromone production and regulation of reproductive division of labor. Therefore, this species is an ideal model system to address the question whether the queen's pheromones are "honest signals" or "suppressive agents". Besides a suite of brood pheromones 
(Arnold et al. 1994), a variety of semiochemicals produced in 15 pheromone glands of the queen (Blum 1992) are known to affect the regulation of division of labor, with the queen mandibular gland pheromone (QMP) playing a central role. QMP not only releases behaviors such as retinue formation (Kaminski et al. 1990) and drone attraction (Gary 1962) among many others, it also has primer effects which inhibit juvenile hormone synthesis in worker bees (Kaatz et al. 1992) and workers refrain from activating their ovaries in its presence (Hoover et al. 2003, 2005). Five major active compounds have been studied in detail: 9-oxo-2(E)-decenoic acid (9-ODA), the two enantiomers of 9hydroxy-2(E)-decenoic acid (9-HDA) as well as the two aromatic compounds methyl $p$ hydroxybenzoate (HOB) and 4-hydroxy-3-methoxyphenylethanol (HVA) (Slessor et al. 1988). 9-ODA, also termed the "queen substance", is by far the most abundant compound in QMP. In contrast, worker's mandibular gland pheromones are dominated by the two fatty acids 10-hydroxydecanoic acid (10-HDAA) and 10-hydroxy-2(E)-decenoic acid (10-HDA) (Plettner et al. 1993). However, this caste specificity is neither absolute nor irrevocable. Shortly after queen removal, some workers start reproducing and mandibular gland pheromones become dominated by 9-ODA while relative proportions of 10-HDAA and 10-HDA decrease (Simon et al. 2001). Similarly, it has been shown that false queens, a particular type of egg-laying workers capable of eliciting retinue behavior, mimic the queen's pheromonal signal (Crewe and Velthuis 1980). Moreover, newly emerged, unmated queens produce a mandibular gland pheromone similar to that of workers (Crewe 1982). In general, the QMP underlies dramatic changes in its quantity and composition during ongoing maturation and ontogenesis with a shift from worker- to queen-like characteristics (Slessor et al. 1990; Pankiw et al. 1996; Engels et al. 1997; Apsegaite and Skirkevicius 1999). The mandibular gland pheromone bouquet is therefore not only influenced by caste (Plettner et al. 1995, 1996) but also by the reproductive capacity of an individual. This plasticity in pheromone production might be an indicator of the "worker control" model in that the composition of mandibular gland pheromones might honestly reflect the emitters' reproductive value for the receiver. However, the evidence in favor of the 'honest signal' model is only correlational. We are not aware of experiments critically testing the two alternative explanations "honest signal" versus "suppressive agent" encoded in the mandibular gland pheromone of honeybees. Laying workers mimicking the QMP signal under competitive conditions may use their pheromones as chemical weapons in establishing dominance hierarchies rather than as markers of their fecundity (Moritz et al. 2000, 2004). In addition, former studies examining maturation-dependent changes in pheromone production in queens have not separated the effects of an individual's age from its reproductive capacity. As queens age, they undergo physiological changes that have been shown to affect their pheromonal output (Rhodes et al. 2007). Thus, the observation that pheromone composition changes with maturation could simply be attributed to the queen's age rather than to her reproductive capacity. This may also explain the high variation in queen mandibular gland pheromone production observed in different studies. Pankiw et al. (1996) showed that 9-ODA and 9-HDA are significantly less abundant in virgin queens than in mated ones. Yet, these queens also differed substantially in age and were either 2 weeks or 1 and 2 years old, respectively. Rhodes et al. (2007) detected amounts of 9-ODA and 9HDA that were higher in virgin queens than in mated ones of the same age, which 
showed that controlling for age when comparing pheromone signals of queens is important.

The aim of this study is to clarify the mode of action of the queen's mandibular gland pheromone in regulating reproductive division of labor in A. mellifera. By keeping the age of honeybee queens constant under different treatments but manipulating their reproductive value for the workers, changes in quantity and quality of the mandibular gland pheromone can be assigned to egg-laying ability only (Keller and Nonacs 1993). Under the "worker control" model, we would expect a tight correlation of queen reproductive value for the workers and pheromone production (as found in Sledge et al. 2001). By comparing virgin queens with egg-laying queens, we can test if the mandibular gland signal is a reliable indicator of ovary activation. In addition, drone-laying queens can be compared with naturally mated ones to determine if the signal is different between equally fecund queens but with offspring that has a different value to colony survival. Drone laying often occurs in old queens which have fully active ovaries but depleted semen stores. The workers typically respond with the rearing of a new queen although the old one is still in the colony. The old queen is eventually superseded by the young queen reared by the workers, and the colony survives. If the mandibular gland signal provides a reliable signal, then virgin, drone-laying, and naturally mated queens should vary in their mandibular gland composition. In contrast, the "queen control" model predicts that queen pheromone production should be regulated independently of queen's reproductive value for the workers (as suggested by Plettner et al. 1993).

\section{Materials and methods}

\section{Queen treatment}

We reared 49 queens with standard apicultural techniques in honeybee colonies $(A$. mellifera carnica) at the apiary of Martin-Luther-University Halle/Wittenberg (Germany) between June and August 2006. After emergence, each queen was introduced into a small colony composed of approximately 1,000 orphaned worker bees randomly chosen from a donor colony. The queens were divided into three experimental groups. In each group, queen reproductive value from the perspective of workers was different rising from treatments 1 to 3 :

1. Virgin queens: 15 queens were prevented from leaving their host colonies because a queen excluder screen was fixed to the hive entrance to prevent nuptial flights. These queens did not lay eggs as their ovaries were not activated, and hence they had the least reproductive value for workers.

2. Drone-laying queens: 17 queens were kept in colonies with queen excluder screens to prevent nuptial flights. Seven days after emergence, they were exposed twice to $\mathrm{CO}_{2}$ for 5 min on two consecutive days. The $\mathrm{CO}_{2}$ treatment induced ovary activation (for details see Mackensen 1947) and subsequent oviposition with the queens starting to lay unfertilized male eggs after 5 to 11 days. These queens had activated ovaries but, from a worker fitness perspective, were disadvantageous since they produced neither queens nor workers and the colony 
would eventually die.

3. Naturally mated queens: 17 queens were free to perform nuptial flights. They returned to their host colonies after mating and started to lay fertilized eggs that developed into female offspring. These queens produced offspring that ensured the highest inclusive fitness for the workers.

Queens similar to these three experimental treatments also occur under natural conditions.

1. Immature virgin queens: after reproductive swarming and queen replacement

2. Drone-laying queens: unmated or old queens with depleted sperm supply

3. Mated queens: reproductive queens laying both male and female eggs.

Queens of treatment groups 2 and 3 were kept in their host hives for 7 days after the first eggs had been laid and the queens had produced at least one small comb of brood $(\times 400$ cells). Thereafter, they were frozen at $-20^{\circ} \mathrm{C}$, decapitated, and each head transferred into $200 \mu \mathrm{l}$ dichloromethane to extract the mandibular gland secretions. The extracts were stored at $-20^{\circ} \mathrm{C}$ until chemical analysis. The virgin queens (treatment group 1) were killed at the same age (between 16 and 26 days) to allow for pairwise comparisons excluding age as an important parameter influencing the results (Crewe and Moritz 1989; Simon et al. 2001).

\section{Chemical analysis of queen mandibular glands}

The heads were removed from the dichloromethane solvent, $40-\mu l$ aliquots were evaporated to dryness under a nitrogen stream, re-dissolved in $15 \mu \mathrm{l}$ internal standard solution containing octanoic acid and tetradecane (each at $0.4 \mathrm{mg} / \mathrm{ml}$ ) in dichloromethane, and derivatized with $15 \mu$ bistrimethylsilyl trifluoroacetamide (Gehrke and Leimer 1971) overnight. One microliter of this solution was injected into a Hewlett Packard 6890 gas chromatograph equipped with a split-splitless inlet, a flame ionization detector, and a methyl siloxane-coated fused silica capillary column (HP-1; $25 \mathrm{~m} \square \mathrm{x} \square 0.2 \mathrm{~mm}, 0.33 \mu \mathrm{m}$ film thickness). Samples were introduced by splitless injection. Nitrogen was used as carrier gas (modified from Simon et al. 2001) with a flow rate of $0.9 \mathrm{ml} / \mathrm{min}$ in constant flow mode. The temperature program was set at $60^{\circ} \mathrm{C}$ ( $1 \mathrm{~min}), 50^{\circ} \mathrm{C} / \mathrm{min}$ heating to $110^{\circ} \mathrm{C}, 3^{\circ} \mathrm{C} / \mathrm{min}$ heating to $220^{\circ} \mathrm{C}$, and $220^{\circ} \mathrm{C}(10 \mathrm{~min})$. The inlet and flame ionization detector were heated at $230^{\circ} \mathrm{C}$ and $320^{\circ} \mathrm{C}$, respectively. Identification of HOB, 9-ODA, HVA, 9-HDA, 10-HAD, and 10-HDAA was based on retention times of synthetic compounds using the Hewlett Packard ChemStation software package. The standard solution containing all six mandibular gland compounds was run at the beginning of chemical analysis and again after every 30th sample. Tetradecane (internal standard) and the external standards were used to determine the relative mass ratios (Gehrke and Leimer 1971) of all tested compounds.

\section{Statistical analysis}

The software package STATISTICA 6.0 (Statsoft) was used to perform statistical analyses. The variance in total weight of each of the six measured QMP components between treatments was analyzed by one-way analysis of variance (ANOVA) and with 
pairwise comparisons by Fisher's least significant difference (LSD) post-hoc test. The same procedure was used to examine the variance of the relative proportions (arcsine transformed) of QMP components. A discriminant analysis was conducted to check whether the three treatment groups could be separated by their QMP composition.

\title{
Results
}

\author{
Absolute amounts of mandibular gland compounds \\ The total quantity of all six mandibular gland compounds (9-ODA, 9-HDA, HOB, HVA, \\ 10-HDAA, and 10-HDA) showed no significant differences among the three treatment \\ groups (ANOVA, $F_{2,46}=0.78, p=0.465$ ). Virgin queens had 124.5 $\pm 84.0 \mu \mathrm{g}$, drone-laying \\ queens had $139.2+88.4 \mu \mathrm{g}$, and naturally mated queens had $160 \pm 75.2 \mu \mathrm{g}$ of mandibular \\ gland secretions (mean $\pm \mathrm{SE}$ ).
}

The absolute amounts of the individual compounds, however, revealed differences between the treatments (Fig. 1). Although amounts of 9-ODA did not significantly differ among treatment groups (ANOVA, $F_{2,46}=0.27, p=0.764$, Fig. 1a), 9-HDA (ANOVA, $F$ $2,46=5.71, p<0.01$ ) showed significant differences between virgin and naturally mated queens (Fisher's LSD, $p=0.001$, Fig. 1b). Whereas the queen-specific aromatic compound $\mathrm{HOB}$ was not significantly altered due to our treatment conditions (ANOVA, $F_{2,46}=0.62$, $p=0.540$, Fig. 1c), the amount of HVA was affected by our experimental treatment (ANOVA, $F_{2,46}=5.04, p<0.01$ ). As for 9-HDA, HVA was significantly different between virgin and naturally mated queens (Fisher's LSD, $p=0.003$, Fig. 1d). However, the largest differences among the treatment groups appeared within the worker-specific fatty acids. The amounts of both 10-HDAA and 10-HDA increased with the queen's reproductive capacity (ANOVA, 10-HDAA $F_{2,46}=1.91, p<0.001 ; 10$-HDA $F_{2,46}=9.61, p<0.001$ ). Posthoc comparisons (Fisher's LSD) revealed significant differences between all groups (with $p \leq 0.05$, Fig. 1e and f). 

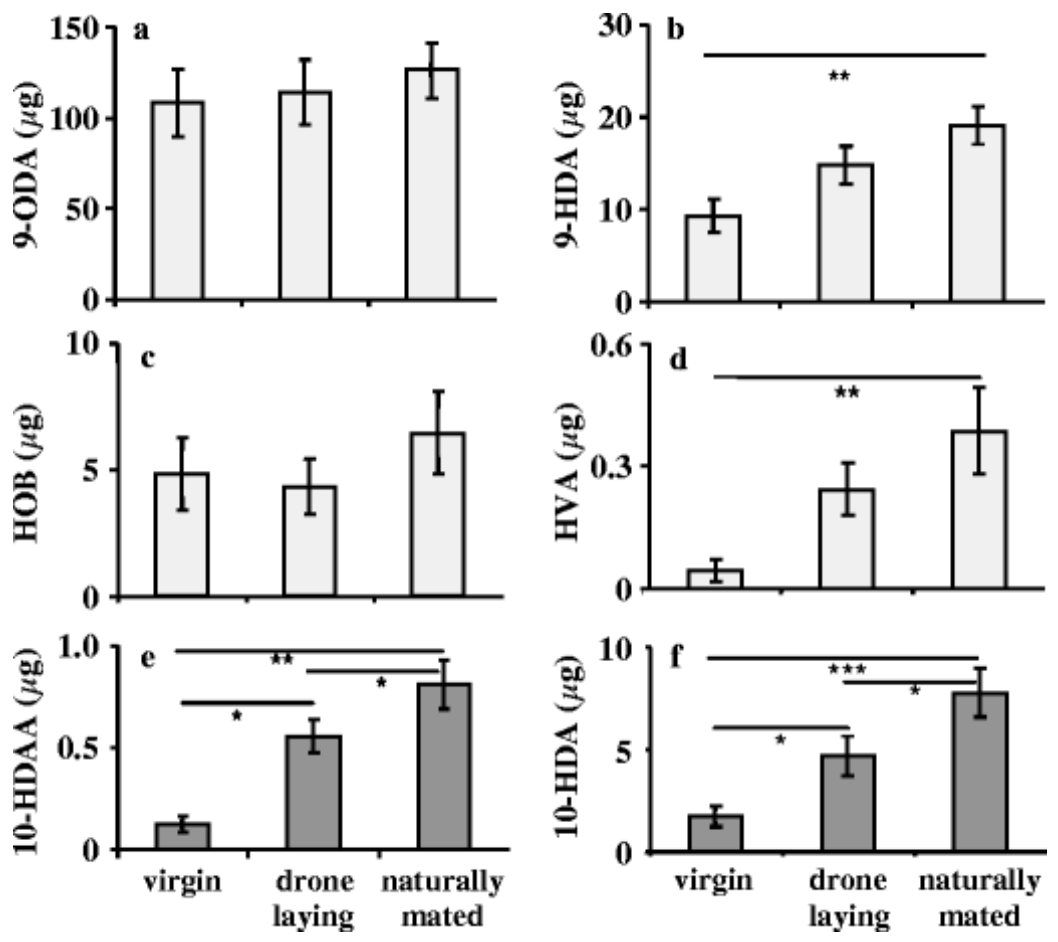

Fig. 1 Absolute amounts (mean \pm SE) of mandibular gland compounds of virgin queens $(n=15)$, drone-laying queens $(n=17)$, and naturally mated queens $(n=17)$. Light grey bars indicate queen-specific and dark grey bars worker-specific components. a 9-ODA: 9oxo-2(E)-decenoic acid; b 9-HDA: 9-hydroxy-2(E)-decenoic acid; c HOB: methyl $p$ hydroxybenzoate; d HVA: 4-hydroxy-3-methoxyphenylethanol; e 10-HDAA: 10hydroxydecanoic acid; f 10-HDA: 10-hydroxy-2(E)-decenoic acid. Asterisks indicate significant differences between two groups: ${ }^{*} p<0.05$; $* * p<0.01 ; * * * p<0.001$ (one-way ANOVA, Fisher's LSD post-hoc test). Note the different scales for the different compounds

We did not find a correlation between the queen's age (16-26 days) and the amount of 9ODA ( $r=0.15, n=49, p=0.85$ ) or the amount of any of the other five QMP components, suggesting that the small variance in age did not affect fatty acid and aromatic compound secretion.

\section{Relative proportions of mandibular gland compounds}

We also analyzed the relative proportions of all compounds in the mandibular gland secretions (Fig. 2) to more strongly focus on the quality of the pheromone rather than the quantity. With increasing queen fecundity, the relative amount of 9-ODA significantly decreased (ANOVA, $F_{2,46}=11.86, p<0.001$, Fisher's LSD with $p<0.05$ for each pairwise comparison, Fig. 2a). Because 9-ODA is the major compound in the secretion, most other compounds show the opposite correlation. The proportion of 9-HDA was lowest in virgin queens, intermediate in drone-laying queens, and highest in naturally mated queens (ANOVA, $F_{2,46}=6.66, p<0.01$, Fig. $2 b$ ). A similar pattern was also found for the worker substances 10-HDAA (ANOVA, $F_{2,46}=15.15, p<0.001$, Fig. 2e) and 10-HDA (ANOVA, 
$F_{2,46}=17.95, p<0.001$, Fig. $2 \mathrm{f}$ ) as well as the aromatic queen compound HVA (ANOVA, $F_{2,46}=3.16, p<0.05$, Fig. 2 d). Only the relative amounts of HOB were not significantly different between the three treatment groups (ANOVA, $F_{2,46}=1.18, p=0.316$, Fig. $2 \mathrm{c}$ ).
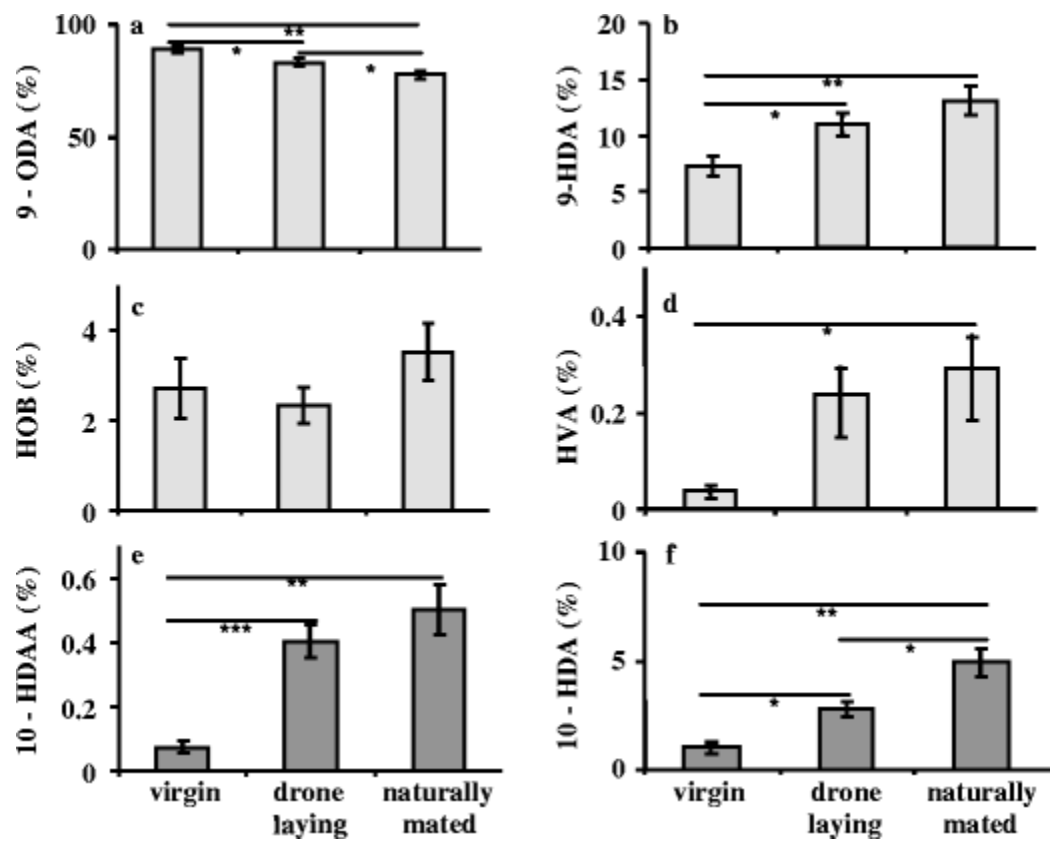

Fig. 2 Relative proportions (mean \pm SE) of mandibular gland compounds per virgin queen $(n=15)$, drone-laying queen $(n=17)$, and naturally mated queen $(n=17)$. Light bars illustrate queen-specific and dark bars worker-specific components. Please note the different scales for the different compounds. a 9-ODA: 9-oxo-2(E)-decenoic acid; b 9HDA: 9-hydroxy-2(E)-decenoic acid; c HOB: methyl $p$-hydroxybenzoate; d HVA: 4hydroxy-3-methoxyphenylethanol; e 10-HDAA: 10-hydrox ydecanoic acid; f 10-HDA: 10-hydroxy-2(E)-decenoic acid. Asterisks indicate significant differences between two groups: $* p<0.05 ; * *<<0.01 ; * * *<<0.001$ (one-way ANOVA, Fisher's LSD post-hoc test)

We also analyzed the ratio of 10-HDAA/9-HDA which has been suggested as a reliable parameter to differentiate between worker $(>1.0)$ and queen-specific signals $(\leq 1.0)$ (Plettner et al. 1993). Similarly, we tested the ratio of 9-ODA/(9-ODA+10-HDAA+10HDA) as a measure of reproductive dominance (Moritz et al. 2004). Here, ratios with values $\geq 0.64$ indicate queen specificity of the pheromone (Crewe 1982). Both analyses yielded similar results and all queens yielded the typical low ratios of 10-HDAA/9-HDA (virgins $0.05 \pm 0.17$; drone layers $0.04 \pm 0.02$; naturally mated $0.04 \pm 0.02$ ) and high 9-ODA ratios (virgins $0.99 \pm 0.0$; drone layers $0.96+0.02$; naturally mated $0.93 \pm 0.04$ ).

\section{Discriminant analysis}

A discriminant analysis was conducted as a multivariate approach to include the relative proportions of all six mandibular gland compounds in a single test (Fig. 3). Function 1 explained $84 \%$ of the variance and divided non-laying from egg-laying queens (Wilk's=0.38, $F_{12,82}=4.18, p<0.01$ ). Only the virgin queens could be significantly 
separated from the other two groups ( $p<0.01$, respectively). All virgins were correctly classified, whereas only $58.82 \%$ of the drone-laying queens and $70.59 \%$ of the naturally mated queens were correctly assigned.

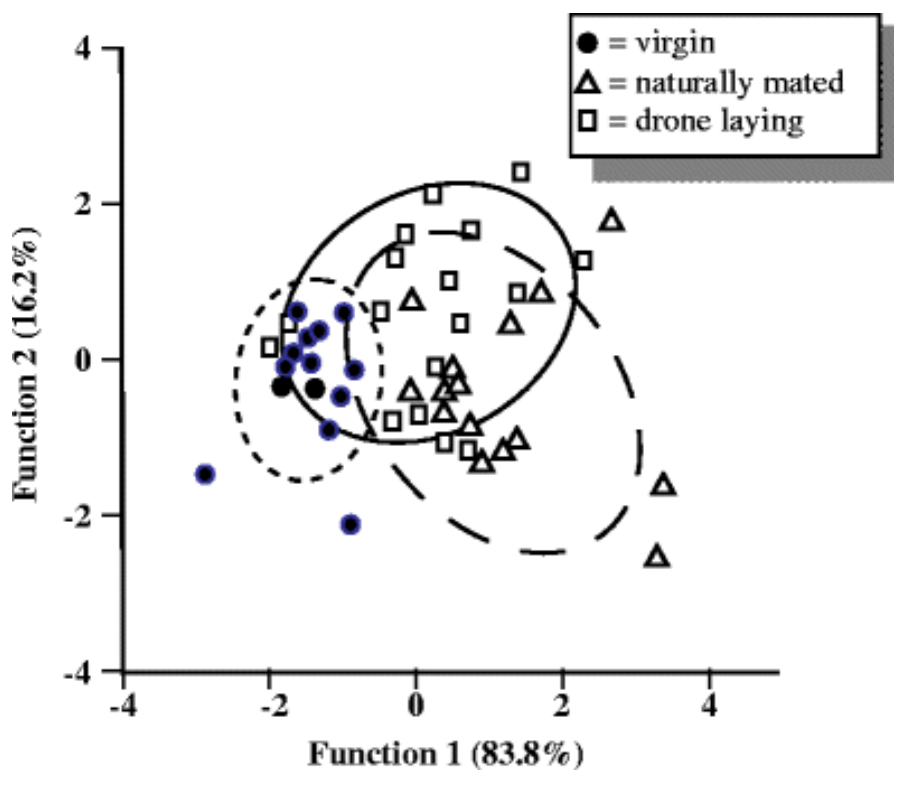

Fig. 3 Discriminant analysis of virgin (filled circles), drone-laying (open squares), and naturally mated (open triangles) queens based on relative proportions of the six mandibular gland compounds (9-ODA, 9-HDA, HOB, HVA, 10-HDAA, and 10-HDA). Virgin queens could be significantly separated from both other groups $(p<0.01)$ but drone-laying and naturally mated queens overlapped in their QMP bouquets

\section{Discussion}

Is the queen's mandibular gland pheromone an honest signal or a suppressive agent? We used the total amounts (quantity) and the relative proportions (quality) of the components of queen mandibular gland secretions in virgin, drone-laying, and naturally mated queens of the same age to address this question.

Pheromone production in the mandibular glands of unmated queens have characteristics intermediate between those of workers and those of mated, egg-laying queens (Apsegaite and Skirkevicius 1995, 1999; Plettner et al. 1997). However, these studies focused on ontogenetic changes in queens, modifying age and reproductive capacity at the same time. We tested mandibular gland compositions of similarly aged queens with different reproductive capacities to eliminate the confounding between age and fecundity. We also tested queens with activated ovaries but different reproductive value for the workers, drone layers, and mated queens. The total quantity of all six mandibular gland compounds (9-ODA, 9-HDA, 10-HDAA, 10-HDA, HOB, and HVA) was neither significantly influenced by the egg-laying queen's reproductive value for workers (drone layers versus mated queens) nor by the queen's ovary activation (virgins versus egg- 
laying queens). This was primarily due to similar amounts of 9-ODA in the bouquet, which represented by far the most abundant chemical constituent of queen mandibular gland pheromones. In contrast, there was a significant rise in the amounts of 9-HDA, 10HDAA, 10-HAD, and HVA but not of HOB, with increasing reproductive capacity. These results seem to contradict those of Pankiw et al. (1996) and Plettner et al. (1997) who found significant increases in total amount of 9-ODA and HOB from virgin/dronelaying queens to mated queens. However, since the queens in their experiments differed not only in reproductive capacity but also in age, these increases might have been due to age differences only, as previously reported by Apsegaite and Skirkevicius (1995) and Engels et al. (1997). A recent study by Rhodes et al. (2007) confirms our data as they showed that 7-day-old virgin queens had higher amounts of 9-ODA than mated queens of the same age, also suggesting that a high amount of 9-ODA is not a reliable cue of reproductive capacity.

Regarding the relative proportions of mandibular gland compounds, significant changes with treatment condition could be detected for all components except HOB. Queen reproductive value was positively correlated with percentages of 9-HDA, 10-HDAA, 10HAD, and HVA, whereas 9-ODA (the most abundant compound) showed a negative correlation. Again, 9-ODA, on its own, cannot be regarded as a reliable signal of fecundity as its proportion should rise and not fall with the queen's reproductive value. One reason for the observed phenomenon might be that 9-ODA plays an essential role in drone attraction (Butler and Fairey 1964) during mating where the queen's signal is airborne and highly diluted. Once in the colony, the queen's mandibular gland secretions are also transferred from worker to worker to regulate many different functions for colony organization. The high 9-ODA concentrations may therefore be more important for virgin than for mated queens.

Fatty acids are differentially produced by workers and queens not only reflecting individual caste membership but also reproductive capacity. Two ratios, that of 10HDAA/9-HDA (Plettner et al. 1993) and that of 9-ODA/(9-ODA+10-HDAA+10-HDA) (Moritz et al. (2004), have been used as indicators of individual fecundity. However, both ratio patterns were not associated with reproductive capacity in our experiment. Queens of all three treatment groups showed similar, highly queen-specific compound ratios. Both ratios are therefore also unlikely to be reliable cues for worker bees to assess their queen's reproductive capacity.

As the efficacy of the queen mandibular gland pheromone as a signal may depend on the composition of the full compound bouquet, a discriminant analysis was used to evaluate changes in overall composition. With this procedure, virgin queens could be separated from the drone-laying and naturally mated queens, but drone-laying and naturally mated queens still clustered together. Hence, even if the mandibular gland composition might indicate the ovary state, the actual reproductive quality of a queen for the workers may not be distinguished by workers based on the QMP compounds alone. If the workers were able to perceive and analyze the compound blend, the overlap of the bouquets is substantial (see Fig. 3) resulting in frequent misclassifications. Even with a multivariate analysis including all mandibular gland compounds, no reliable cue of reproductive 
capacity to discriminate between drone layers and fully fertile queens of the same age emerges.

Surprisingly, we observed an increase of both amounts and relative proportions of 10HDAA and 10-HDA with rising reproductive capacity of the queen. However, both chemicals are usually predominantly found in the mandibular glands of workers (Crewe 1982) and do not seem to play any role in the regulation of worker reproduction. Therefore, although our experiments provide no test of this idea, it is rather improbable that these fatty acids form a signal of reproductive capacity. The increase in worker compounds is more likely to reflect a general rise in biosynthetic activity in the mandibular glands, with increased pheromone production associated with ovary activation, because also the queen compounds 9-HDA and HVA rise with increasing queen fecundity (Fig. 1). 9-HDA is the second most abundant constituent of the QMP in a variety of Apis species (A. mellifera, Slessor et al. 1988; A. dorsata, Plettner et al. 1997; A. cerana and A. nigrocinta, Keeling et al. 2001) and a rise in 9-HDA production could be documented with the queen's ongoing maturation (Pankiw et al. 1996; Engels et al. 1997). 9-HDA seems to act only in combination with other QMP components to mediate behaviors such as eliciting of workers' retinue response (Slessor et al. 1988), suppression of worker ovarian development (Hoover et al. 2003), and inhibition of queen rearing (Pettis et al. 1997). The rise in HVA seems to be associated with ovary activation that typically occurs after mating (Slessor et al. 1990; Engels et al. 1997). Beggs et al. (2007) showed that HVA reduces dopamine levels in the honeybee's brain. Because feeding of dopamine to worker bees elevates rates of ovarian activation (Dombroski et al. 2003), HVA might be a potential agent within QMP involved in regulating worker sterility. Alas, HVA alone has not been demonstrated to cause suppression of worker ovaries. The aromatic compound, HOB, also appears to be associated with mating (Pankiw et al. 1996; Plettner et al. 1997) but its specific functions have not yet been investigated. Suppression of brain dopamine levels could not be confirmed for HOB (Beggs et al. 2007). Similarly, neither Rhodes et al. (2007) nor our results showed that the production of HOB was correlated with the queen's reproductive capacity and HOB seems unlikely to play a role in fecundity signalling.

In spite of the complex composition of QMP, the queen substance, 9-ODA, is the key compound ensuring regulation of reproductive division of labor and the other compounds only play an ancillary role. In contrast to the other compounds, 9-ODA alone can almost completely prevent ovary activation in workers (Butler and Fairey 1963). Hence, if 9ODA were a reliable, honest signal, it should rise with increasing reproductive value of the queen for the workers. This was clearly not the case in our study. We found no significant differences in 9-ODA total amounts of virgin, drone-laying, and naturally mated queens. The relative proportions even declined with increasing reproductive capacity. So, if 9-ODA affects ovary activation in workers independent of the queen's reproductive status, it is clearly not the cue compound that might serve as an honest signal. It seems that the queen substance controls the workers' ovary activation rather than workers refrain from reproduction after assessing their queen's reproductive capacity. We therefore suggest that the queen substance should be regarded as a suppressive agent. 
Recent research on "worker control" of reproductive division of labor in other social insect species emphasizes the evolutionary significance of honest signalling of queen fecundity (e.g., in wasps, Polistes dominulus, Sledge et al. 2001; and ants, Dinoponera quadriceps, Monnin et al. 1998; Myrmecia gulosa, Dietemann et al. 2003). For the "worker control" model to operate in honeybees, pheromones other than QMP must be responsible for the production of reliable signals of reproductive capacity. The pheromones produced by the queen's Dufour's gland have been shown to closely correlate with fecundity (Katzav-Gozansky et al. 1997, 2001; Dor et al. 2005); however, also here no differences were found in ester levels between virgin and egg-laying queens (Martin and Jones 2004). Since pheromones produced by the brood (Pettis et al. 1997) have been shown to interfere with worker ovary activation and workers are able to detect a lack of brood (as shown for Polistes wasps, Liebig et al. 2005), brood pheromones are currently the most likely candidates to serve as a reliable signal of queen fertility for the workers.

\section{References}

Apsegaite V, Skirkevicius A (1995) Quantitative and qualitative composition of extracts from virgin and mated honey bee queens (Apis mellifera L.). Pheromones 5:23-36

Apsegaite V, Skirkevicius A (1999) Content of (E)-9-oxo-2-decenoic acid in pheromones of honeybee (Apis mellifera L.) queens. Pheromones 6:27-32

Arnold G, Le Conte Y, Trouiller J, Hervet H, Chappe B, Masson C (1994) Inhibition of worker honeybee ovaries development by a mixture of fatty acid esters from larvae. C R Acad Sci Paris Sci Vie 317:511-515

Beggs KT, Glendining KA, Marechal NM, Vergoz V, Nakamura I, Slessor KN, Mercer AR (2007) Queen pheromone modulates brain dopamine function in worker honey bees. Proc Nat Acad Sci USA 104:2460-2464

Blum MS (1992) Honey bee pheromones. In: Graham JM (ed) The hive and the honey bee. Dadant, Hamilton, pp 373-394

Bourke AFG (1988) Worker reproduction in the higher eusocial Hymenoptera. Q Rev Biol 63:291-311

Butler CG, Fairey EM (1963) The role of the queen in preventing oogenesis in worker honeybees. J Apic Res 2:14-18

Butler CG, Fairey EM (1964) Pheromones of the honeybee: biological studies of the 
mandibular gland secretion of the queen. J Apic Res 3:65-76

Crewe RM (1982) Compositional variability: the key to the social signals produced by honeybee mandibular glands. In: Breed MD, Mitchener ED, Evans HE (eds) The biology of social insects. Westview, Boulder, pp 318-322

Crewe RM, Velthuis HHW (1980) False queens: a consequence of mandibular gland signals in worker honeybees. Naturwissenschaften 67:467-469

Crewe RM, Moritz RFA (1989) Mandibular gland fatty acid variation in workers and queens of Apis mellifera intermissa Buttel-Reepen. Z Naturforsch 44c:590-596

D’Ettorre P, Heinze J, Schulz C, Francke W, Ayasse M (2004) Does she smell like a queen? Chemoreception of a cuticular hydrocarbon signal in the ant Pachycondyla inverse. J Exp Biol 207:1085-1091

Dietemann V, Peeters C, Liebig J, Thivet V, Hölldobler B (2003) Cuticular hydrocarbons mediate discrimination of reproductives and nonreproductives in the ant Myrmecia gulosa. Proc Nat Acad Sci USA 100:10341-10346

Dombroski TCD, Simones Z, Bitondi M (2003) Dietary dopamine causes ovary activation in queenless Apis mellifera workers. Apidologie 34:281-289

Dor R, Katzav-Gozansky T, Hefetz A (2005) Dufour's gland pheromone as a reliable fertility signal among honeybee (Apis mellifera) workers. Behav Ecol Sociobiol 58:270276

Endler A, Liebig J, Schmitt T, Parker JE, Jones GR, Schreier P, Hölldobler B (2004) Surface hydrocarbons of queen eggs regulate worker reproduction in a social insect. Proc Natl Acad Sci USA 101:2945-2950

Engels W (1986) The concept of chemical communication in arthropods as realized in social bee reproduction. Adv Invert Reprod 4:285-296

Engels W, Rosenkranz P, Adler A, Taghizadeh T, Lübke G, Francke W (1997) Mandibular gland volatiles and their ontogenetic patterns in queen honey bees, Apis mellifera carnica. J Insect Physiol 43:307-313

Fletcher DJC, Blum M (1981) Pheromonal control of dealation and oogenesis in virgin queen fire ants. Science 212:73-75 
Fletcher DJC, Ross KG (1985) Regulation of reproduction in eusocial Hymenoptera. Annu Rev Entomol 30:319-343

Gary NE (1962) Chemical mating attractants in the queen honeybee. Science 136:773774

Gehrke CW, Leimer K (1971) Trimethylsilylation of amino acids derivatization and chromatography. J Chromatog 57:219-238

Hamilton WD (1964) The genetical evolution of social behaviour. J Theor Biol 7:1-52

Hoover SER, Keeling CI, Winston ML, Slessor KN (2003) The effect of queen pheromones on worker honey bee ovary development. Naturwissenschaften 90:477-480

Hoover SER, Oldroyd BP, Wossler TC, Winston ML (2005) Anarchistic queen honey bees have normal queen mandibular pheromones. Insectes Soc 52:6-10

Kaatz HH, Hildebrandt H, Engels W (1992) Primer effect of queen pheromone on juvenile hormone biosynthesis in adult worker honey bees. J Comp Physiol B 162:588592

Kaminski LA, Slessor KN, Winston ML, Hay NW, Borden JH (1990) Honeybee response to queen mandibular pheromone in laboratory bioassays. J Chem Ecol 16:841850

Katzav-Gozansky T, Soroker V, Hefetz A (1997) Plasticity of caste-specific Dufour's gland secretion in the honey bee (Apis mellifera L.). Naturwissenschaften 84:238-241

Katzav-Gozansky T, Soroker V, Ibarra F, Francke W, Hefetz A (2001) Dufour's gland secretion of the queen honeybee (Apis mellifera): an egg discriminator pheromone or a queen signal? Behav Ecol Sociobiol 51:76-86

Keeling CI, Otis GW, Hadisoesilo S, Slessor KN (2001) Mandibular gland component analysis in the head extracts of Apis cerana and Apis nigrocincta. Apidologie 32:243-252

Keller L, Nonacs P (1993) The role of queen pheromones in social insects: queen control or queen signal? Anim Behav 45:787-794

Liebig J, Monnin T, Turillazzi S (2005) Direct assessment of queen quality and lack of worker suppression in a paper wasp. Proc R Soc B 272:1339-1344 
Mackensen O (1947) The effect of carbon dioxide on initial oviposition of artificially inseminated and virgin queen bees. J Econ Entomol 40:344-349

Martin SJ, Jones GR (2004) Conservation of biosynthetic pheromone pathways in Apis. Naturwissenschaften 91:232-236

Monnin T, Malosse C, Peeters C (1998) Solid-phase microextraction and cuticular hydrocarbon differences related to reproductive activity in the queenless ant Dinoponera quadriceps. J Chem Ecol 24:473-490

Moritz RFA, Simon UE, Crewe RM (2000) Pheromonal contest between honeybee workers (Apis mellifera capensis). Naturwissenschaften 87:395-397

Moritz RFA, Lattorff HMG, Crewe RM (2004) Honeybee workers (Apis mellifera capensis) compete for producing queen-like pheromone signals. Proc R Soc Lond B Suppl 271:98-100

Naumann K, Winston ML, Slessor KN, Prestwich GD, Webster FX (1991) Production and transmission of honey bee queen (Apis mellifera L.) mandibular gland pheromone. Behav Ecol Sociobiol 29:321-332

Page RE, Erickson EH (1988) Reproduction by worker honey bees (Apis mellifera L.). Behav Ecol Sociobiol 23:117-126

Pankiw T, Winston ML, Plettner E, Slessor KN, Pettis JS, Taylor OR (1996) Mandibular gland components of European and Africanized honey bee queens (Apis mellifera L.). $\mathrm{J}$ Chem Ecol 22:605-615

Peeters C, Monnin T, Malosse C (1999) Cuticular hydrocarbons correlated with reproductive status in a queenless ant. Proc R Soc Lond B 266:1323-1327

Pettis JS, Higo HA, Pankiw T, Winston ML (1997) Queen rearing suppression in the honey bee-evidence for a fecundity signal. Insectes Soc 44:311-322

Plettner E, Slessor KN, Winston ML, Robinson GE, Page RE (1993) Mandibular gland components and ovarian development as measures of caste differentiation in the honey bee (Apis mellifera L.). J Insect Physiol 39:235-240

Plettner E, Sutherland GRJ, Slessor KN, Winston ML (1995) Why not be a queen? Regioselectivity in mandibular secretions of honeybee castes. J Chem Ecol 21:10171029 
Plettner E, Slessor KN, Winston ML, Oliver JE (1996) Caste-selective pheromone biosynthesis in honeybees. Science 271:1851-1853

Plettner E, Otis GW, Wimalaratne PDC, Winston ML, Slessor KN, Pankiw T, Punchihewa PWK (1997) Species- and caste-determined mandibular gland signals in honeybees (Apis). J Chem Ecol 23:363-377

Rhodes JW, Lacey MJ, Harden S (2007) Changes with age in queen honey bee (Apis mellifera) head chemical constituents (Hymenoptera: Apidae). Sociobiol 5:11-22

Seeley TD (1979) Queen substance dispersal by messenger workers honeybee colonies. Behav Ecol Sociobiol 5:391-415

Seeley TD (1985) Honeybee ecology: a study of adaptation in social life. Princeton University Press, Princeton

Simon UE, Moritz RFA, Crewe RM (2001) The ontogenetic pattern of mandibular gland components in queenless worker bees (Apis mellifera capensis Esch.). J Insect Physiol $47: 735-738$

Sledge MF, Boscaro F, Turillazzi S (2001) Cuticular hydrocarbons and reproductive status in the social wasp Polistes dominulus. Behav Ecol Sociobiol 49:401-409

Slessor KN, Kaminski LA, King GGS, Borden JH, Winston ML (1988) Semiochemical basis of the retinue response to queen honey bees. Nature 332:354-356

Slessor KN, Kaminski LA, King GGS, Winston ML (1990) Semiochemicals of the honeybee queen mandibular glands. J Chem Ecol 16:851-860

Visscher PK (1989) A quantitative study of worker reproduction in honey bee colonies. Behav Ecol Sociobiol 25:247-254

West-Eberhard M (1981) Intragroup selection and the evolution of insect societies. In: Alexander RD, Tinkle DW (eds) Natural selection and social behavior. Chiron, New York, pp 3-17 